\title{
Gene discovery using next-generation pyrosequencing to develop ESTs for Phalaenopsis orchids
}

\author{
Yu-Yun Hsiao ${ }^{1,2+}$, Yun-Wen Chen ${ }^{3 \dagger}$, Shi-Ching Huang ${ }^{1}$, Zhao-Jun Pan ${ }^{1}$, Chih-Hsiung Fu ${ }^{4}$, Wen-Huei Chen ${ }^{2}$, \\ Wen-Chieh Tsai ${ }^{2,3^{*}}$ and Hong-Hwa Chen ${ }^{1,2,3^{*}}$
}

\begin{abstract}
Background: Orchids are one of the most diversified angiosperms, but few genomic resources are available for these non-model plants. In addition to the ecological significance, Phalaenopsis has been considered as an economically important floriculture industry worldwide. We aimed to use massively parallel 454 pyrosequencing for a global characterization of the Phalaenopsis transcriptome.

Results: To maximize sequence diversity, we pooled RNA from 10 samples of different tissues, various developmental stages, and biotic- or abiotic-stressed plants. We obtained 206,960 expressed sequence tags (ESTs) with an average read length of $228 \mathrm{bp}$. These reads were assembled into 8,233 contigs and 34,630 singletons. The unigenes were searched against the NCBI non-redundant (NR) protein database. Based on sequence similarity with known proteins, these analyses identified 22,234 different genes (E-value cutoff, $\mathrm{e}^{-7}$ ). Assembled sequences were annotated with Gene Ontology, Gene Family and Kyoto Encyclopedia of Genes and Genomes (KEGG) pathways. Among these annotations, over 780 unigenes encoding putative transcription factors were identified.
\end{abstract}

Conclusion: Pyrosequencing was effective in identifying a large set of unigenes from Phalaenopsis. The informative EST dataset we developed constitutes a much-needed resource for discovery of genes involved in various biological processes in Phalaenopsis and other orchid species. These transcribed sequences will narrow the gap between study of model organisms with many genomic resources and species that are important for ecological and evolutionary studies.

\section{Background}

The family of Orchidaceae is the largest family of flowering plants and the number of species may exceed 25,000 [1]. Like all other living organisms, present-day orchids have evolved from ancestral forms as a result of selection pressure and adaptation. They show a wide diversity of epiphytic and terrestrial growth forms and have successfully colonized almost every habitat on earth. Factors promoting orchid species richness include specific interaction between the orchid flower and

\footnotetext{
* Correspondence: tsaiwc@mail.ncku.edu.tw; hhchen@mail.ncku.edu.tw

+ Contributed equally

'Department of Life Sciences, National Cheng Kung University, Tainan 701,

Taiwan

2Orchid Research Center, National Cheng Kung University, Tainan 701,

Taiwan

Full list of author information is available at the end of the article
}

pollinator [2], sequential and rapid interplay between drift and natural selection [3], obligate interaction with mycorrhiza [4], and epiphytism which is true for most of all orchids and probably two-thirds of the epiphytic flora of the world.

The radiation of the orchid family has probably taken place in a comparatively short period as compared with that of most flowering plant families, which had already started to diversify in the Mid-Cretaceous [5]. The time of origin of orchids is in dispute, although Dressler suggests that they originated 80 to 40 million years ago (Mya; late Cretaceous to late Eocene) [6]. Recently, the origin of the Orchidaceae was dated with a fossil orchid and its pollinator. The authors showed that the most recent common ancestor of extant orchids lived in the late Cretaceous (76-84 Mya) [7]. They also suggested that Epidendroideae and Orchidoideae, two of the

\section{() Biomed Central}


largest orchid subfamilies, which together represent > $95 \%$ of living orchid species, began to diversify early in the Tertiary (65 Mya) [7].

According to molecular phylogenetic studies, Orchidaceae comprise 5 subfamilies: Apostasioideae, Cypripedioideae, Vanilloideae, Orchidoideae and Epidendroideae. The Apostasioideae is considered the sister group to other orchids. Vanilloideae diverged just before Cypripedioideae. Both subfamilies have relatively low numbers of genera and species. Most of the taxonomic diversity in orchids is in 2 recently expanded sistersubfamilies: Orchidoideae and especially Epidendroideae $[8,9]$. Orchids are known for their diversity of specialized reproductive and ecological strategies. For successful reproduction, the production of labellum and gynostemium (a fused structure of androecium and gynoecium) to facilitate pollination is well documented and the co-evolution of orchid flowers and pollinators is well known $[10,11]$. In addition, the especially successful evolutionary progress of orchids may be explained by mature pollen grains packaged as pollinia, pollinationregulated ovary/ovule development, synchronized timing of micro- and mega-gametogenesis for effective fertilization, and the release of thousands or millions of immature embryos (seeds without endosperm) in a mature capsule [12]. However, despite their unique developmental reproductive biology, as well as specialized pollination and ecological strategies, orchids remain under-represented in molecular studies relative to other species-rich plant families [13]. The reasons may be associated with the large genome size, long life cycle, and inefficient transformation system of orchids.

The genomic sequence resources currently available for orchids are limited. Very recently, a sketch of the Phalaenopsis orchid genome from sequencing the ends of 2 bacterial artificial chromosome libraries of $P$. equestris was reported [14]. In addition, a number of studies have developed expressed sequence tags (ESTs) resources for orchids by using Sanger sequencing [15-18]. Fewer than 12,000 ESTs, including 5,593 from P. equestris, 2,359 from P. bellina, 1,080 from Oncidium Gower Ramsey, and 2,132 from Vanda Mimi Palmer, have been deposited in public database. These studies have highlighted the utility of cDNA sequencing for discovering candidate genes for orchid floral development $[19,20]$, floral scent production $[16,21]$ or flowering time [22] in the absence of a genomic sequence. However, a comprehensive description of the full complement of gene expressed in orchids remains unavailable.

Massively parallel 454 pyrosequencing has become feasible for increasing sequencing depth and coverage while reducing time, labour, and cost $[23,24]$. This technology can be used to deeply explore the nature and complexity of a given transcriptional universe. 454 sequencing of transcriptomes for model organisms has confirmed that the relatively short reads produced by this technology can be effectively assembled and used for gene discovery [25,26]. In addition, the superior performance of this technology has been demonstrated in several studies [27], including those of mustard weed Arabidopsis thaliana [28,29], the model legume Medicago truncatula [21], maize Zea may [30,31], the tree Eucalyptus grandis [32], chestnut [33], oil crop Olea europaea [34], oilseed rape Brassica napus [35], and the antimalarial plant Artemisia annua [36].

The genus Phalaenopsis Blume (Orchidaceae), a beautiful and one of the most popular ornamental flowers exported worldwide, comprises 66 species according to the latest classification by Christenson [37]. The species are found throughout tropical Asia and the larger islands of the Pacific Ocean. In Taiwan, 2 of the native species, $P$. equestris and $P$. aphrodite subsp. formosana, are usually used as parents for breeding. P. equestris possesses several favorable commercial traits such as numerous spikes and branches and multitudinous and colorful flowers. P. aphrodite subsp. formosana has a perfect arrangement of flower positions at the spike and an elegant flower shape with extended longevity. The flowers of both species are scentless. Many of the scent traits in the $P$. hybrids are mainly derived from $P$. bellina and/or P. violaceae, the native species in Malaysia. Both $P$. equestris and $P$. aphrodite subsp. formosana are diploid plants with 38 chromosomes $(2 \mathrm{n}=2 \mathrm{x})$, which are small and uniform in size $(<2 \mu \mathrm{m})$. The estimated haploid genome sizes are 1,600 $\mathrm{Mb}$ (3.37 pg/diploid genome) and 1,300 Mb (2.80 pg/ diploid genome) for $P$. equestris and $P$. aphrodite subsp. formosana, respectively, which are relatively small in genus of Phalaenopsis [38]. The 2 species could be considered model organisms for studying orchid biology because of their relative small genome size [39], high performance of culture system and well applicable functional genomic tools such as genetic transformation [40-42] and virus-induced gene silencing system [43].

In this report, we provide the first comprehensive characterization of the transcriptome of Phalaenopsis orchids by massively parallel 454 pyrosequencing. To expansively cover the Phalaenopsis orchid transcriptome and facilitate identifying sets of genes involved in a broad range of biological processes, we developed the EST set from 10 samples derived from 3 different species of Phalaenopisis (Table 1). Based on data corresponding to a single run on the GS FLX sequencer, almost 42 million bases were assembled into $\sim 43,000$ pieces of putative transcripts and the majority of these have been annotated and functionally classified. All the sequences were deposited in OrchidBase (http:// 140.116.25.218/EST, [44]) and Short Read Archive 
Table 1 Samples used for transcriptome analysis

\begin{tabular}{|c|c|}
\hline Species & Tissues \\
\hline \multirow[t]{7}{*}{ Phalaenopsis equestris } & inflorescence \\
\hline & flower bud \\
\hline & root \\
\hline & young leaf \\
\hline & old leaf \\
\hline & cold stressed leaf \\
\hline & Erwinia chrysanthemi -infected leaf \\
\hline \multirow[t]{2}{*}{ Phalaenopsis aphrodite } & protocorm \\
\hline & cold night temperature -induced spike \\
\hline Phalaenopsis bellina & Day 5 post anthesis flower \\
\hline
\end{tabular}

(SRA) division of the GenBank repository (accession no. SRA030758.2). These results can provide the means for future genome-wide orchid biology and biotechnology research in Phalaenopsis.

\section{Results}

Sequencing and assembly of 454 pyrosequenced ESTs In total, 207,110 ESTs (minimal size > $50 \mathrm{bp}$ ) averaging 230 bp were generated from one pyrosequencing run. Cleaning (removal of primer, polyA tail, etc) of the raw sequences resulted in a total of 206,960 high-quality reads with an average length of 228 bp nucleotides totaling $42 \mathrm{Mb}$. After assembly using GS FLX gsAssembler, these reads were assembled into 8,233 contigs and 34,630 singletons under the criteria of minimum 40 bases overlap with at least $95 \%$ identity. The average length of contigs and singletons was $364 \mathrm{bp}$ and $201 \mathrm{bp}$, respectively. These contigs and singletons represented up to 42,863 unigenes. The length distribution of unigenes and their component reads are summarized in Table 2 and Additional file 1 and Additional file 2. Our assembly also included a larger proportion of long contigs ( $16 \%$ of the contigs were $\geq 500 \mathrm{bp}$ ) (Additional file 1) than the $8 \%$ reported by Novaes et al. [32]. The unigene set was also compared to the ESTs derived from $P$. equestris [11] and P. bellina [12]. About 16.2\% (E-value cutoff, $\mathrm{e}^{-10}$ ) of the unigenes could be matched to the published Phalaenopsis ESTs (Figure 1). In addition,

Table 2 Summary of Phalaenopsis EST data

\begin{tabular}{lr}
\hline Total Bases & $42,034,787$ \\
High-quality Reads & 206,960 \\
Average Read Length & 228 \\
Number of Contigs & 8,233 \\
Average Contig Length & 364 \\
Range of Contig Length & 72 to 4234 \\
Number of Reads in Contigs & 172,330 \\
Number og Singletons & 34,630 \\
Number of Unigene Sequences & 42,863 \\
\hline
\end{tabular}

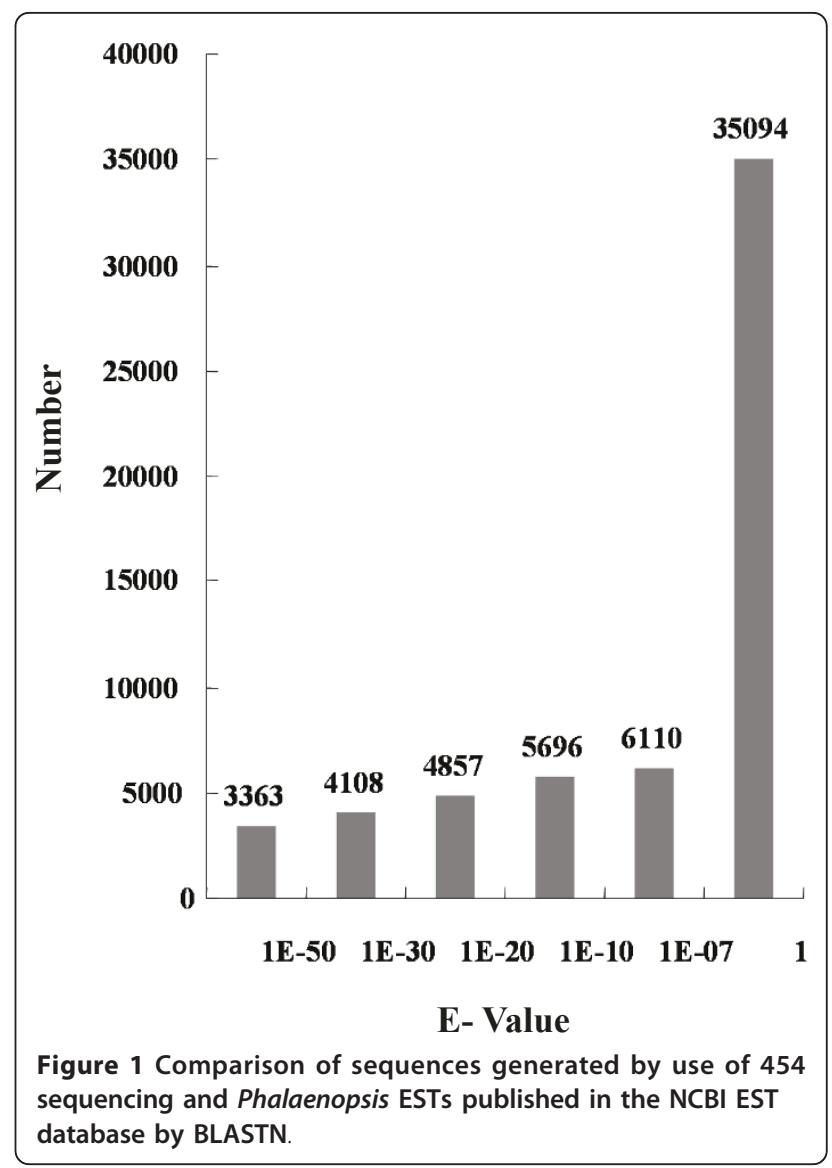

different sized contigs were selected to recalculate the BLAST hits. Result showed that the percentage of hits was proportion to contig size (400 bp-600 bp, 29.84\%; 600 bp-800 bp, 46.6\%; 800 bp-1000 bp, 52.63\%; > 1000 bp, $64.92 \%$; Figure 2). Furthermore, the previously available ESTs derived from Phalaenopsis orchids were BLAST against ESTs generated by this study. Results showed that among 4,875 unigenes, 3,503 (71.9\%) matched the ESTs produced by 454 pyrosequencing.

The unigenes were searched against the NCBI nonredundant (NR) protein database by use of the BLASTX algorithm. Among the 42,863 unigenes, 22,234 (51.9\%) had at least one significant alignment to existing genes in the database (E-value cutoff, $\mathrm{e}^{-7}$ ) (Figure 3), and 20,684 of these $(93.03 \%)$ had an open reading frame (ORF). A majority (48.1\%) of the pyrosequencing assemblies did not match any known sequences in the database. To analyze effects of fragment size on annotation efficiency, we compared the percentage of hits between different sized ESTs with and without homology at Evalue $<10^{-7}$ (Figure 4). The result showed that $42.88 \%$ of genes without homology and $13 \%$ of those with homology were $<200 \mathrm{bp}$. Thus, short reads may have a low level of annotation. In addition, it is also possible 


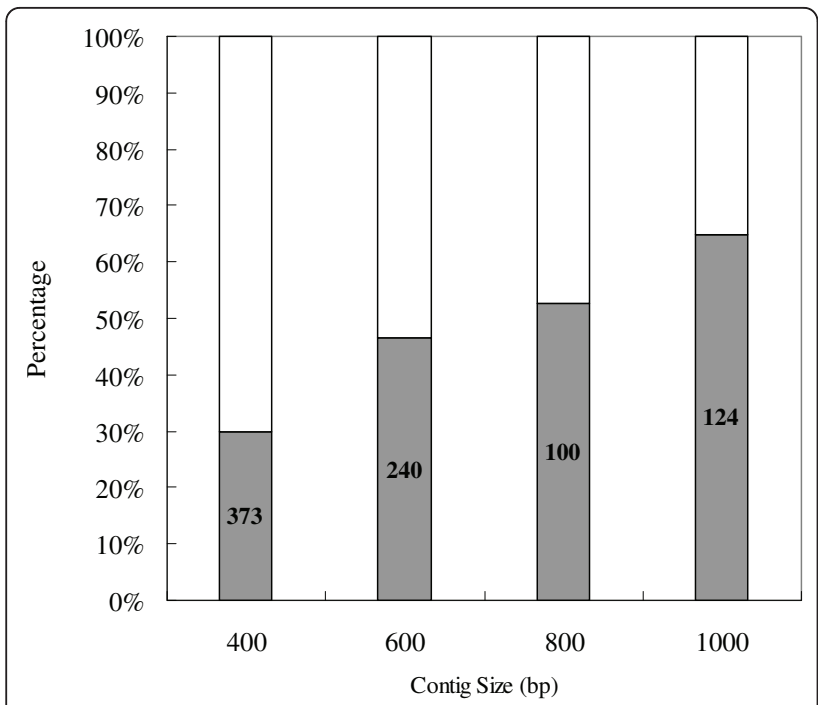

Figure 2 Comparison of percentage of hits among different sized contigs against Phalaenopsis ESTs published in the NCBI EST database by BLASTN (E-value $<10^{-10}$ ).

that unannotated reads may likely represent novel genes. Alternatively, these sequences might correspond to divergent 5' or 3' regions of genes.

\section{Functional annotation of novel transcripts}

To determine the possible functions of genes tagged, we used the Gene Ontology (GO) classification system for plants developed at TAIR [45] (http://www.arabidopsis. org/help/helppages/go_slim_help.jsp). The functions of genes identified cover various biological processes, molecular functions and cellular components (Figure 5). In total, 10,427 of the 42,863 transcripts were assigned to biological processes. The largest proportion of functionally assigned ESTs fell into protein metabolism (11\%)

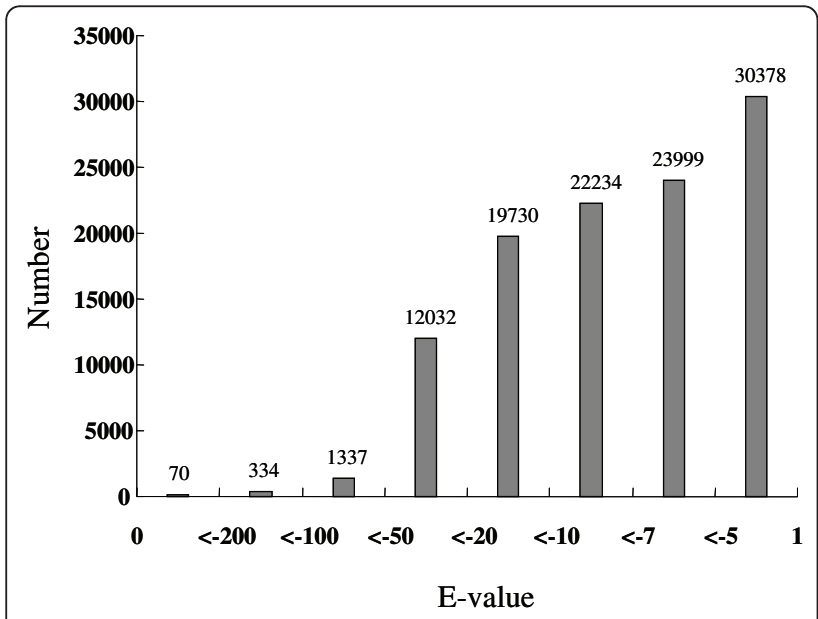

Figure 3 The number of sequence hits against the NCBI nonredundant (NR) database by BLASTX.

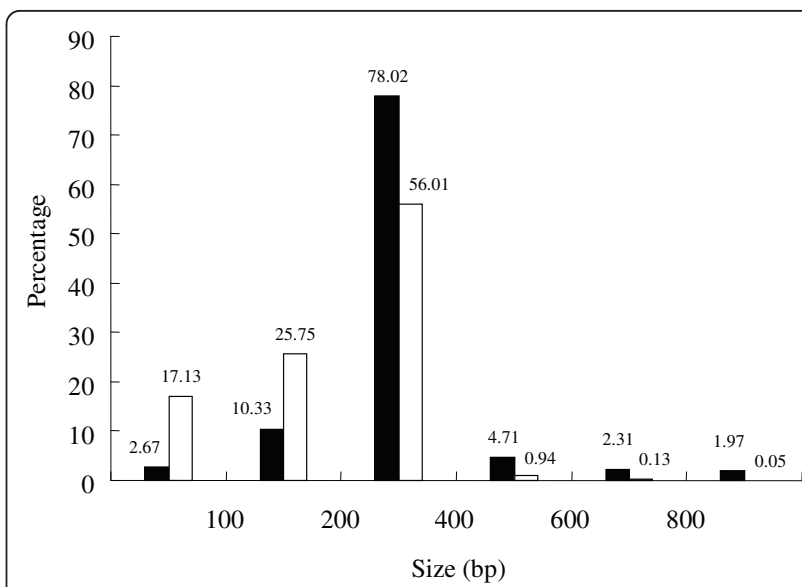

Figure 4 Comparison of percentage of hits in the NR database for different sized ESTs with (black bars) and without (white bars) homology (E-value $<10^{-7}$ ).

and transport (8\%) except of unknown biological processes $(20 \%)$ and other cellular processes $(14 \%)$. Among the molecular functions, 9,518 out of a total 42,863 transcripts were assigned in this category. The molecular functions most represented were hydrolase activity (12\%), transferase activity (8\%) and nucleotide binding (8\%) except for other enzyme activity (19\%) and unknown molecular functions (17\%). Among the cellular components, 9,685 out of a total 42,863 transcripts were assigned in this category. Chloroplast (18\%) and plasma membrane $(12 \%)$ are the most represented categories in cellular components except for unknown cellular components (22\%).

These ESTs obtained from a non-normalized cDNA library could be used to reveal global gene expression patterns as deduced from transcript abundance. The transcripts highly expressed in Phalaenopsis tissues are listed in Table 3. The most abundant ESTs coded for cytochrome P450-like protein precursor (2.27\%), followed by triple gene block 3 (1.98\%) and cytochrome P450 monooxygenase (1.28\%). These ESTs probably correspond to the most highly expressed genes in the Phalaenopsis. Plant systems utilize a diverse array of cytochrome P450 monooxygenases in their biosynthetic and detoxicative pathways. High expression of the cytochrome P450 gene family suggests that these genes are important for orchid subsistence and adaptation to the environment. The high expression of triple gene block 3 raised the interesting question of whether the sequence samples were infected by Cymbidium mosaic virus (CymMV) or if the gene is included in the Phalaenopsis genome. Therefore, we screened other genes of the same CymMV in the EST dataset. In addition to triple gene block 3, several genes of CymMV were found, including 30 unigenes of RNA dependent RNA 


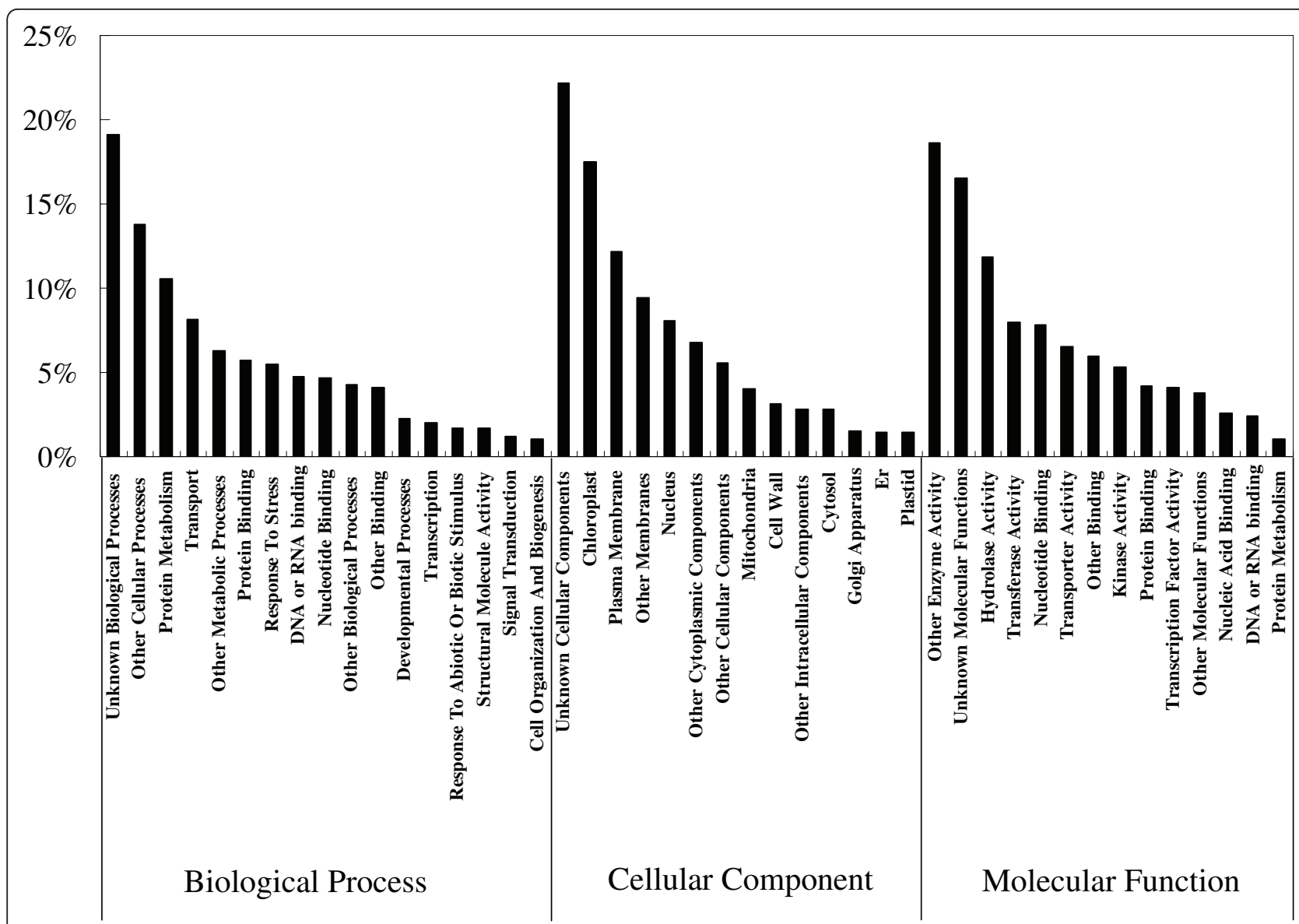

Figure 5 Representation of genome ontology assignments for Phalaenopsis ESTs derived from 454 sequencing. The GO Slim Classification for Plants developed at TAIR was used to characterize the ESTs functionally.

polymerase, 24 of coat protein, 4 of triple gene block 1 , and 2 of triple gene block 2 . These transcripts showed significant expression in Phalaenopsis, which indicates that some of the experimental materials used here may have been infected with virus prior to the sampling.

Analysis of a large number of ESTs has revealed ancient polyploidy throughout the major angiosperm lineages [46,47]. It would be interesting to analyze how many subfamilies exist in very high number of ESTs to evaluate the possibility of gene duplication in Phalaenopsis orchids. We set more stringent criteria for assembly (a minimum of 40 bases of overlap with $97 \%$ and 99\% identity) and found a greater number of unigenes (Table 3), suggesting that some genes may have been undergone gene duplication. However, more evidence is needed to solve the causes that lead to the formation of paralogous genes, such as whole-genome duplication, tandem gene duplication or segmental duplication.

Table 3 Highly abundant transcripts detected in Phalaenopsis

\begin{tabular}{|c|c|c|c|c|c|}
\hline Putative Function & Organism & E-value & $\begin{array}{l}\text { Number of Component } \\
\text { Reads }\end{array}$ & $\begin{array}{l}\text { Number of Contigs } \\
\text { (97\% identity) }\end{array}$ & $\begin{array}{l}\text { Number of Contigs } \\
\text { (99\% identity) }\end{array}$ \\
\hline $\begin{array}{l}\text { Putative P450- like protein } \\
\text { precursor }\end{array}$ & Zea mays & $5.00 \mathrm{E}-20$ & 4,705 & 2 & 4 \\
\hline Triple gene block 3 & $\begin{array}{l}\text { Cymbidium mosaic } \\
\text { virus }\end{array}$ & $3.00 \mathrm{E}-22$ & 4,100 & n.d. & n.d. \\
\hline $\begin{array}{l}\text { Cytochrome P450 } \\
\text { monooxygenase }\end{array}$ & Sorghum bicolor & $2.00 \mathrm{E}-08$ & 2,653 & 5 & 7 \\
\hline LLA- 1378 & Lilium longiflorum & $3.00 \mathrm{E}-28$ & 2,269 & 3 & 3 \\
\hline Hypothetical protein & Sorghum bicolor & $3.00 \mathrm{E}-15$ & 1,668 & 3 & 4 \\
\hline
\end{tabular}

n.d.: not determined 


\section{Gene families and Pathways}

To evaluate the effectiveness of the orchid transcriptome library, we categorized the assembled unigenes through the use of Arabidopsis proteome as targets. In total, 4,833 unigenes were classified into 130 gene families representing 73.9\% (130/176) of Arabidopsis gene families (Additional file 3). We also mapped assembled unigenes into the KEGG Pathways including metabolism, genetic information processing, environmental information processing, cellular processes, and organism systems (http://www.genome.jp/kegg/pathway.html). A total of 7,885 unigenes were mapped onto KEGG Pathways (Table 4). Among these, 6,269 unigenes were related to metabolism, 1,078 unigenes corresponded to genetic information processing, 121 unigenes mapped to environmental information processing, 213 unigenes were classified as cellular processes, and 204 unigenes belonged to organism systems (Table 4). The presence genes for these essential cellular processes suggest that these sequences account for most of the comprehensive Phalaenopsis transcriptome.

Previously, we identified the major compounds emitted from $P$. bellina flowers to be monoterpenes, including linalool and geraniol [13]. Identification of the potential genes involved in the biosynthetic pathways for terpenoid precursors will be important for understanding the regulation of scent biosynthesis in orchids. In our 454 sequence dataset, 50 unigenes assembled from 209 reads were found potentially related to the methylerythritol phosphate pathway (MEP) and mevalonate pathway (MVA) (Additional file 4). Analysis of previous ESTs from $P$. bellina showed 8 unigenes assembled from 20 reads were potentially related to the MEP and MVA pathways (Figure 6). The use of 454 pyrosequencing identified more genes and more ESTs per gene constituted in the terpenoid backbone biosynthesis than did Sanger sequencing (Figure 6). At least one unigene was found to correspond to the enzymes participating in the two pathways, except the third step of the MEP pathway (Figure 6). Thus, the large amount of transcriptomic information provided by 454 pyrosequencing may accelerate the progress for the study of scent production and regulation in orchids.

\section{Transcription factors}

Because transcription factors control the expression of a genome and play important roles in all aspects of the life cycle of higher plants, we characterized the transcription factor-associated ESTs from the transcriptome of Phalaenopsis by using rice transcription factor sequences downloaded from the Plant Transcription Factor Database (http://planttfdb.cbi.pku.edu.cn/) as queries. In the Phalaenopsis transcriptome, we identified 786 unigenes consisted of 2,317 reads encoding putative transcription factors, occupying $1.83 \%(786 / 42,863)$ of the unigenes of Phalaenopsis transcriptome. Compared to the $5.7 \%$ of plant genes that have been shown to be transcription factor genes [48], 1.83\% of genes related to

Table 4 Unigenes mapped in KEGG Pathways

\begin{tabular}{llll}
\hline KEGG Pathways & Sub-pathways of KEGG Pathway & Number of Unigenes & Number of reads \\
\hline Metabolism & & 6269 & 43325 \\
& Glycan Biosynthesis and Metabolism & 84 & 137 \\
& Xenobiotics Biodegradation and Metabolism & 22 & 95 \\
& Metabolism of Other Amino Acids & 162 & 575 \\
& Biosynthesis of Polyketides and Terpenoids & 146 & 7957 \\
& Carbohydrate Metabolism & 1229 & 19261 \\
& Overview & 2360 & 1201 \\
& Biosynthesis of Other Secondary Metabolites & 179 & 1860 \\
& Lipid Metabolism & 450 & 678 \\
& Nucleotide Metabolism & 236 & 707 \\
Metabolism of Cofactors and Vitamins & 188 & 2998 \\
& Amino Acid Metabolism & 639 & 7160 \\
Genetic Information Processing & Energy Metabolism & 574 & 6944 \\
Organismal Systems & & 1078 & 384 \\
Environmental Information Processing & Replication and Repair & 149 & 1962 \\
\hline & Transcription & 301 & 1674
\end{tabular}




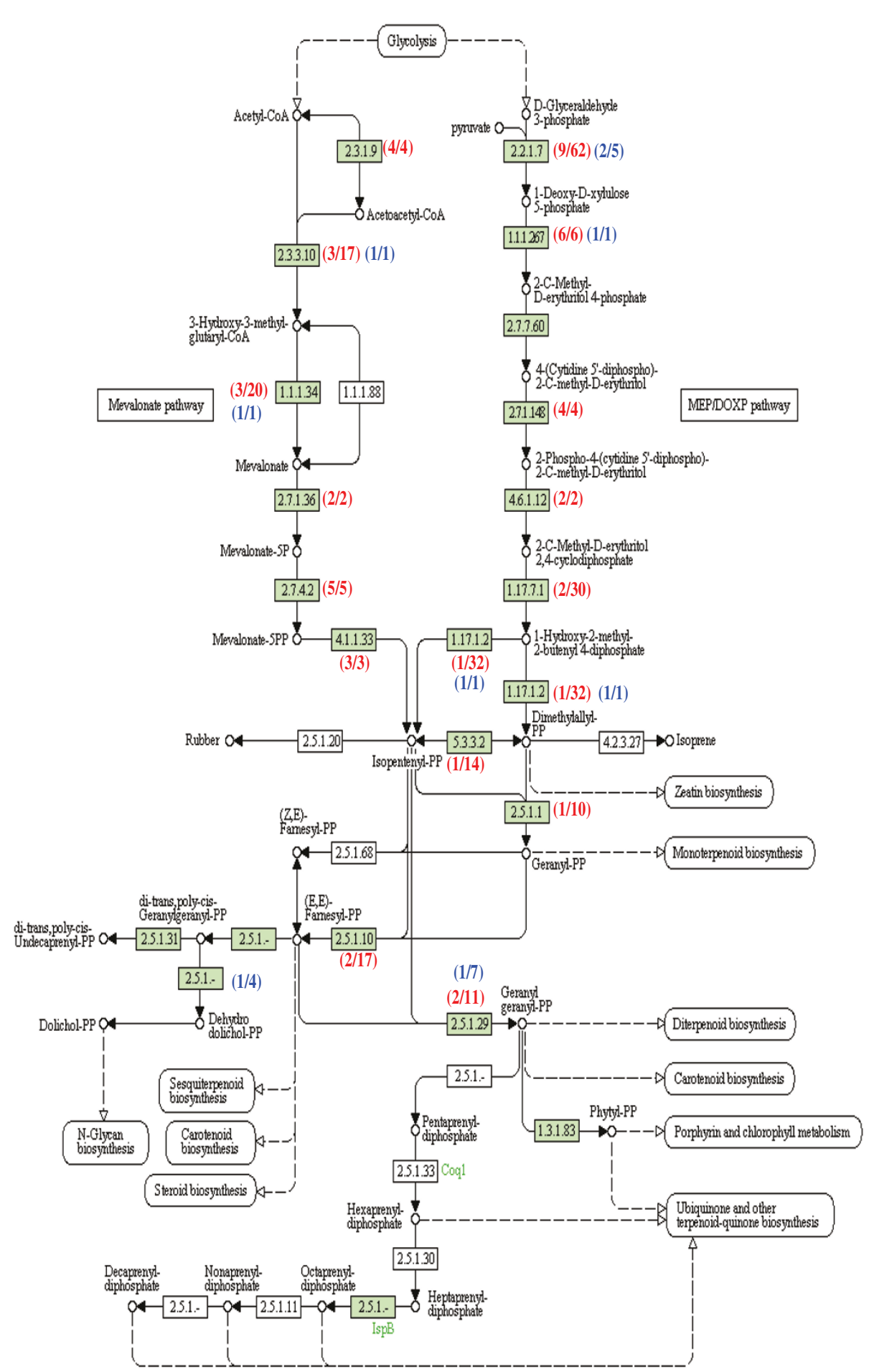

Figure 6 Graphic representation of terpenoid backbone biosynthesis pathways, including cytosolic mevolonate pathway and plastic methylerythritol phosphate pathway, for Phalaenopsis orchids. The red and blue numbers represent the ESTs generated by this study and derived from P. bellina [16], respectively, that are homologous to genes involved in the terpenoid backbone biosynthesis pathway. The first number in the bracket is the number of unigenes corresponding to the catalytic gene in the pathway, and the second number is the number of reads for the unigene. 
transcription factors in Phalaenopsis is low. To analyze the underestimation, we mapped all unigenes to 9 fulllength cDNAs (FL-cDNAs) encoding MADS-box proteins (PeMADS1 PeMADS9) derived from $P$. equestris. In total, 33 unigenes could be mapped to the $9 \mathrm{FL}$ cDNAs. Among the 33 unigenes, 5 are located in untranslated regions, and the other two are short fragments (<90 bp) located within coding regions. However, these seven unigenes were not identified as transcription factor genes. These results suggest that one of the reasons for an underestimation of transcription factor genes in Phalaenopsis can be explained by sequences corresponding to divergent 5' or 3' regions of genes and/or they are short reads per se.

The most abundantly expressed transcription factor gene families, $\mathrm{C} 3 \mathrm{H}$ and $\mathrm{AP} 2 / \mathrm{ERF}$, accounted for a full $32.2 \%(746 / 2,317)$ of the overall transcription factor expression (Figure 7). In addition, bHLH (4.9\%), MYB $(4.7 \%)$ and NAC (4.5\%) families were found in turn (Figure 7). These five families occupied approximately
$46.3 \%$ of expressed transcription factors. However, five families of transcription factors including LFY, M-type, STAT, VOZ, and WOX were not detected. The few families that could not be found might result from inadequate sampling of the transcriptome or genes that are truly rarely expressed. Large-scale efforts in deeper sampling and sequencing of the transcriptome will help completely identify genes related to of transcription factor families in orchids.

\section{Discussion}

As the most species rich and diversified family, Orchidaceae has mesmerized botanists for centuries. As for most other non-model plant species, we lack genetic and genomic resources for molecular biological study. Although a precise estimate of transcriptome coverage is unattainable without the full genomic sequence, the massively parallel pyrosequencing characterization can be considered an initial step for functional genomics studies in Phalaenopisis. From 206,960 sequence reads,

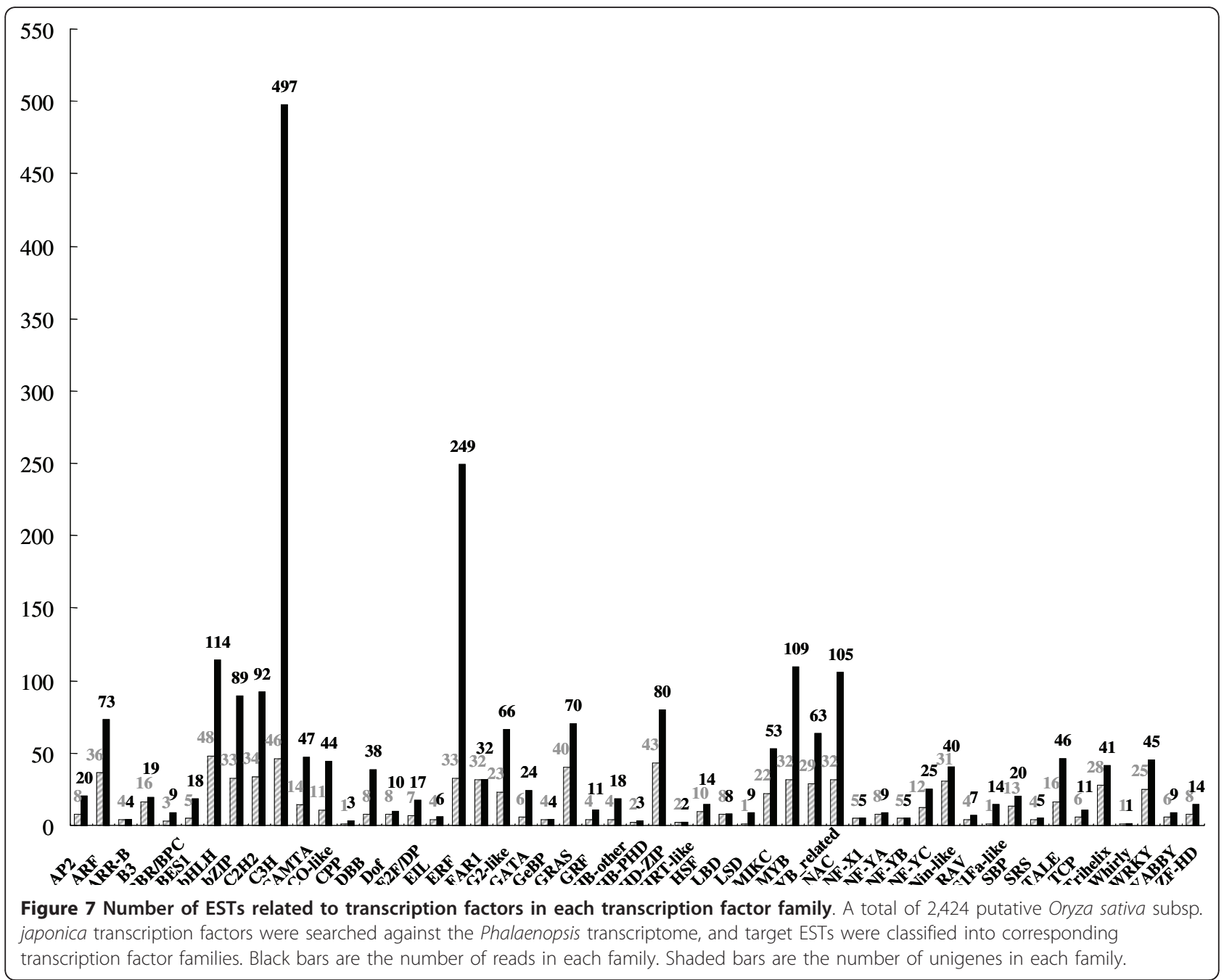


we assembled data for 42,863 unigenes consisting of 8,233 contigs and 34,630 singletons from Phalaenopsis. Although a high number of transcripts are short-length reads which may result in several assembled contigs and singletons for each gene, the dataset we report here still provides a plentiful dataset of different genes representing a substantial part of the transcriptome of orchids, which in turn reflects these plants' sophisticated designs for successful pollination, reproduction and adaptation to the environment.

Homology searches showed that $48.1 \%$ of the ESTs have no significant similarities to any other protein sequences in public databases. About $42.88 \%$ of these ESTs are $<200 \mathrm{bp}$, indicating that the short size has a negative effect on successful annotation. However, these genes may perform specific roles in orchids and be quite divergent from those of other plant species. The orchids, indeed, have diverse specialized reproductive and ecological strategies for adaptive radiation. On the other hand, we could not reliably annotate a high proportion of unigenes lacking assignment of a putative function because they did not cover the full length of the transcript or because they represent untranslated regions.

Comparing the distributions of the functional categories among ESTs provides support for the expression levels of the different gene classes. The transcripts with the first and third highest expression we found for Phalaenopsis were homologous to the members of cytochrome P450 (4.55\%). Plant cytochromes P450 catalyze a wide variety of monooxygenation/hydroxylation reactions in primary and secondary metabolism. Genomic sequencing projects have revealed that cytochromes P450 genes represent approximately $1 \%$ of the total gene annotations for each plant species $[49,50]$. In addition to revealing the highest transcript expression in Phalaenopsis, the next-generation transcriptome sequencing also generated 94 members of the cytochrome P450 family. The extraordinary expression level and remarkable diversification of this gene family may have led to the Phalaenopsis orchid survival ability. The transcript with the second highest level of expression was homologous to triple gene block 3 (1.98\%) of CymMV. We also found genes with significant expression that were homologous to RNA dependent RNA polymerase, coat protein, triple gene block 1 and triple gene block 2 of CymMV. Even though we found no substantial virusinfected symptoms in our samples, some of the experimental materials have been infected with virus prior to the sampling. We also found transcripts with high expression (1.1\%) that were homologous to LLA-1378 derived from lily (Lilium longiflorum). This transcript is found in immature anther, tepal, pistil, stem and leaf in lily [51], however it has an as yet unknown function.
Dissection of function of these genes might be a useful direction for further study of orchid biology.

The fact that whole-genome duplication often gives rise to species-rich groups of organisms, such as $>23,000$ species of Asteraceae and > 19, 400 species of Fabaceae, highlights that polyploidy can facilitate diversification and speciation of organisms [52,53]. The Orchidaceae contains more than 25,000 species and has successfully colonized almost every habitat on earth. Whole-genome duplication may also have occurred in the orchid genome. Based on the results from analyzing how many subfamilies exist with very high number of ESTs, we suggested gene duplication probably have occurred on these genes. However, these gene duplication events may be caused by whole-genome duplication, tandem gene duplication or segmental duplication. Only after completeness of whole-genome sequencing of Phalaenopsis has been performed, it will be possible to differentiate whole-genome duplications from segmental and tandem duplications by mapping chromosome locations of the duplicated genes or blocks of genes.

To evaluate whether the sequences annotated in this study include all genes expressed in these tissues, developmental stages, and treatments, we searched for a number of genes involved in metabolic pathways and homologous to members characterized in Arabidopsis gene families. The genes associated with metabolic pathways were based on the KEGG database of pathways and those for gene family on the TAIR database of Arabidopsis proteome. The rationale for these searches was that those essential genes must be expressed to maintain cellular functions, so failure to find these sequences in the transcriptome would reflect either inadequate sequencing depth or ineffective annotation. For the pathways considered here, essentially all genes involved in the pathways were found except those involved in anthocyanin biosynthesis. For the 176 gene families in Arabidopsis, total 4,833 unigenes were classified into 130 gene families occupying more than $70 \%$ (130/176) of Arabidopsis gene families. A caution for these finding is that high levels of expression might be expected for some essential house-keeping genes, leading them to be well represented in even an incomplete transcriptome sequencing effort. To account for this possibility, we searched for genes associated with transcription factors. Because of their more restricted spatial and temporal expression profiles, transcription factor genes are not expected to be as highly expressed as essential housekeeping genes in whole-organism libraries. We successfully identified genes from nearly all the transcription factor families considered (51/56, 91\%). The few genes that could not be found might result from incomplete annotation or inadequate sampling of the transcriptome 
or they may be truly not expressed. Overall, these searches support that the collection of annotated sequences we produced represents a reasonably broad description of the Phalaenopsis transcriptome. These sequences of expressed transcripts will be very useful for genome annotation of Phalaenopsis genome in the future.

Analysis of expression profiles of transcription factors in the transcriptome of Phalaenopsis is meaningful because these are master-control proteins in all living cells. Surprisingly, we found that $\mathrm{C} 3 \mathrm{H}$ and AP2/ERF families together represented more than $30 \%$ of expression of Phalaenopsis transcription factors. The $\mathrm{C} 3 \mathrm{H}$ family has been reported to be involved in Arabidopsis embryogenesis [54], shoot apical meristem maintenance [55], drought tolerance [56], and response to abscisic acid in Craterostigma plantagineum [57]. The AP2/ERF superfamily is defined by the AP2/ERF domain, of about 60 to 70 amino acids, and is involved in DNA binding. A combination of genetic and molecular approaches has been used to characterize a series of regulatory genes of the AP2/ERF family. The members of this family are involved in regulating various biological processes related to growth and development, as well as various responses to environmental stimuli. This family includes genes related to drought [58], high salt concentration [58], low temperature [59], diseases [60,61], and the control of ovule development and flower organ growth [62]. Understanding the functions of these genes will advance our understanding of the great morphological diversity and successful adaptation of orchids. However, we did not find the transcription factor families LFY, M-type, STAT, VOZ, and WOX, in the Phalaenopsis transcriptome. These families might either be rarely expressed, or might not have appeared in our cDNA sampling.

\section{Conclusion}

Thanks to recent advances in next-generation sequencing technology, we have applied RNA-seq to facilitate transcriptome analysis of orchids which present important biological questions but lack a fully sequenced genome. Our findings represent substantial contributions to the publicly accessible expressed sequences for the Orchidaceae family. With the whole genome sequencing of $P$. equestris in progress, this collection of ESTs is a valuable resource that will be immediately useful for researchers, allowing for correction of assemblies, annotation, and construction of gene models to establish accurate exon-intron boundaries. Application of these resources through the common language of nucleotide sequences will greatly enhance the insights into the reproductive success of orchids.

\section{methods}

\section{Plant materials and cDNA library construction}

Phalaenopsis equestris, P. aphrodite subsp. formosana and $P$. bellina were grown without fungal symbiosis in greenhouses at National Cheng Kung University under natural light and controlled temperature ranging from $23^{\circ} \mathrm{C}$ to $27^{\circ} \mathrm{C}$. To maximize the diversity and effectively collect sequences from expressed genes of orchids, we collected 10 samples from different tissues, developmental stages and treatments (Table 1). Inflorescences, flower buds, leaves and roots were sampled from the 3year-old $P$. equestris. Young leaves were collected as they emerged. Old leaves were taken at the fourth leaf counting down from the newly emerged one. The coldstressed leaves were collected from old leaves of 3-yearold plants treated for 4 hrs at $4^{\circ} \mathrm{C}$. Because Erwinia chrysanthemi is one of the most serious pathogens infecting Phalaenopsis, old leaves were infected with $E$. chrysanthemi to induce the expression of pathogenrelated genes. Protocorms were 20-day-old germinating seeds of $P$. aphrodite subsp. formosana grown on tissuecultured plates without fungal symbiosis. Cool nightinduced spikes were sampled from 3-year-old P. aphrodite subsp. formosana treated with cool night temperature $\left(28^{\circ} \mathrm{C}\right.$ day $/ 20^{\circ} \mathrm{C}$ night $)$ for 2 weeks to induce spike emergence [63]. P. bellina flowers with a strong fragrance were collected on day 5 post-anthesis [16]. Collected samples were frozen immediately in liquid nitrogen and stored at $-80^{\circ} \mathrm{C}$ until used.

Total RNA from each sample was extracted separately following the method described by [19]. Poly-A RNA was prepared from each total RNA sample using the Oligotex ${ }^{@}$ mRNA Mini kit (Qiagen, Ontario, Canada). Samples of $0.5 \mu \mathrm{g}$ mRNA from each sample were combined into a single large pool and mixed well. This single large, equally-mixed pool was the source for the cDNA library construction. The cDNA library was constructed using the SMART cDNA synthesis Kit (BD Clontech, Mountain View, CA) according to the manufacturer's instructions.

\section{Pyrosequencing and assembly}

In preparation for 454 sequencing, $5 \mu \mathrm{g}$ of the cDNA sample was nebulized to a mean fragment size of $600 \pm$ $50 \mathrm{bp}$, end repaired and adapter ligated according to previously published literature [23]. After streptavidin bead enrichment and DNA denaturation, singlestranded molecules were titrated onto derivatized Sepharose beads and then amplified by emulsion PCR. A second streptavidin bead enrichment followed emulsion breaking, the bead-attached DNAs were then denatured with $\mathrm{NaOH}$, and sequencing primers were annealed. One 454 pyrosequencing run was carried out 
with use of a GS FLX sequencer. A 454 SFF file containing raw sequences and sequence quality information can be access through the SRA web site under accession number SRA030758.2.

Low quality data (base call score $<10$ ) were trimmed from the ends of individual sequences. Sequences shorter than $50 \mathrm{bp}$ after processing were excluded from the analysis. For assembly, GS FLX gsAssembler was used with minimum 40 bases overlap with at least $95 \%$ identity.

\section{Sequence analysis and GO classification}

All sequences were queried for their similarity to known sequences by use of a BLASTX algorithm [64] against the "nr" protein database. Sequence similarity was considered significant at E-value $<10^{-7}$ and the "best hits" annotation was used to represent proteins similar to those encoded by the contigs and singletons. The BLAST score (bits) used the BLOSUM 62 matrix and Existence 11, Extension 1 Gap costs for BLASTX. The GO Slim Classification for Plants, developed at TAIR (http://www.arabidopsis.org/help/helppages/go_slim_help.jsp) was used to characterize the ESTs functionally. The GO identifier of the best hit (with a cutoff of 1e-7) was attributed to the sequence. This step allowed putative functions to be assigned on the basis of the classification proposed by GO.

\section{Characterization of ESTs by Arabidopsis Gene Family and KEGG Pathways}

The TAIR9 A. thaliana annotated protein databases (ftp://ftp.arabidopsis.org/home/tair/Genes/TAIR9_genome_release/TAIR9_sequences) was downloaded. The protein sequence set was BLAST against Phalaenopsis contigs and singletons with use of the TBLASTN programs. Sequence similarity was considered significant at an E-value $<10^{-7}$. Unique sequences with BLAST matches were mapped to TAIR Gene Families and KEGG Pathways of Arabidopsis for further analysis. The TAIR Gene Family information contains 8,693 genes in 176 gene families updated on September 26, 2009. The KEGG Pathways for Arabidopsis contains 6,756 genes in 121 pathways released on May 11, 2010.

\section{Identification of putative transcription factor-related ESTs} The protein sequences of predicted transcription factors for rice were downloaded from the Plant Transcription Factor Database (PTFDB; http://planttfdb.cbi.pku.edu. $\mathrm{cn} /$ ). PTFDB contains information on 2,424 rice (Oryza sativa subsp. japonica) transcription factors in 56 families. For identification of transcription factor-related ESTs from Phalaenopsis, the protein sequence set of each predicted rice transcription factor family was
BLAST against Phalaenopsis contigs and singletons with use of the TBLASTN programs. Sequence similarity was considered significant at E-value $<10^{-7}$.

\section{Additional material}

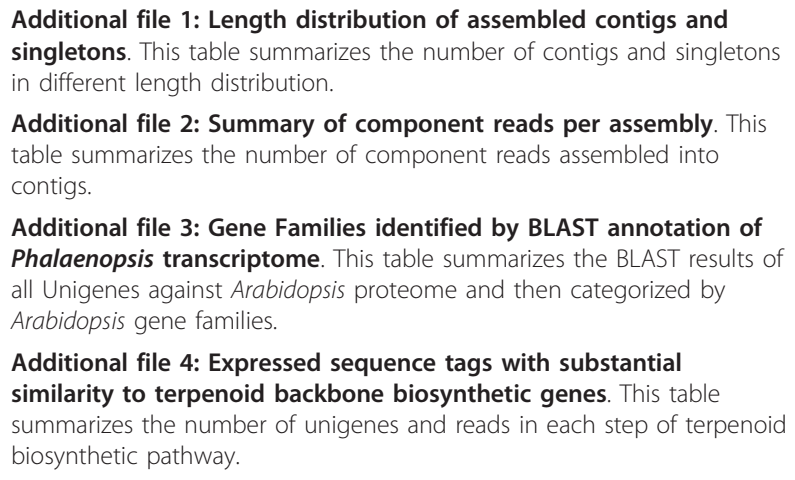

Additional file 4: Expressed sequence tags with substantial similarity to terpenoid backbone biosynthetic genes. This table summarizes the number of unigenes and reads in each step of terpenoid biosynthetic pathway.

\section{Acknowledgements}

We thank Dr. Michel Delseny for providing critical comments on the manuscript. We also thank Miss Laura Smales for detailed editing the manuscript. We thank Dr. David T.H. Ho for his long-term support of our work on orchid genomics. This work was supported by the National Science Council, Taiwan (grant no. NSC97-2317-B-024-001).

\section{Author details}

${ }^{1}$ Department of Life Sciences, National Cheng Kung University, Tainan 701, Taiwan. ${ }^{2}$ Orchid Research Center, National Cheng Kung University, Tainan 701, Taiwan. ${ }^{3}$ Institute of Tropical Plant Sciences, National Cheng Kung University, Tainan 701, Taiwan. ${ }^{4}$ Department of Engineering Science, National Cheng Kung University, Tainan 701, Taiwan.

\section{Authors' contributions}

YYH conceived the study and design, participated in the library construction and data analysis. YWC performed the design of the bioinformatic analyses. SCH carried out RNA extraction and CDNA synthesis. ZJP contributed to the sample collection. CHF constructed the platform for displaying metabolic pathway. WHC suggested and offered the orchid materials. WCT participated in the design and coordination, and drafted the manuscript. HHC initiated the project, contributed to the experimental design and edited the manuscript. All authors read and approved the final manuscript.

Received: 10 January 2011 Accepted: 12 July 2011

Published: 12 July 2011

\section{References}

1. Atwood JT: The size of Orchidaceae and the systematic distribution of epiphytic orchids. Selbyana 1986, 9:171-186.

2. Cozzolino S, Widmer A: Orchid diversity: an evolutionary consequence of deception? Trends Ecol Evol 2005, 20:487-494.

3. Tremblay RL, Ackerman JD, Zimmerman JK, Calvo RN: Variation in sexual reproduction in orchids and its evolutionary consequence: a spasmodic journey to diversification. Biol J Linn Soc 2005, 84:1-54.

4. Otero JT, Flanagan NS: Orchid diversity - beyond deception. Trends Ecol Evol 2006, 21:64-65.

5. Crane PR, Friis EM, Pedersen KR: The origin and early diversification of angiosperms. Nature 1995, 374:27-33.

6. Dressler RL: The orchids: Natural history and classification Cambridge, Massachusetts, USA: Harvard University Press; 1981.

7. Ramirez SR, Gravendeel B, Singer RB, Marshall CR, Pierce NE: Dating the origin of the Orchidaceae from a fossil orchid with its pollinator. Nature 2007, 448:1042-1045. 
8. Rudall PJ, Bateman RM: Roles of synorganisation, zygomorphy and heterotopy in floral evolution: the gynostemium and labellum of orchids and other lilioid monocots. Biol Rev 2002, 56:784-795.

9. Górniaka M, Paunb O, Chase MW: Phylogenetic relationships within Orchidaceae based on a low-copy nuclear coding gene, Xdh: Congruence with organellar and nuclear ribosomal DNA results. $\mathrm{Mol}$ Phylogenet Evol 2010, 56:784-795.

10. Yu H, Goh CJ: Molecular Genetics of Reproductive Biology in Orchids. Plant Physiol 2001, 127:1390-1393.

11. Schiestl FP, Peakall R, Mant JG, Ibarra F, Schulz C, Franke S, Francke W: The chemistry of sexual deception in an orchid-wasp pollination system. Science 2003, 302:437-438.

12. Tsai WC, Hsiao YY, Pan ZJ, Kuoh CS, Chen WH, Chen HH: The role of ethylene in orchid ovule development. Plant Sci 2008, 175:98-105.

13. Peakall R: Speciation in the Orchidaceae: confronting the challenges. Mol Ecol 2007, 16:2834-2837.

14. Hsu C-C, Chung Y-L, Chen T-C, Lee Y-L, Kuo Y-T, Tsai W-C, Hsiao Y-Y, Chen $Y-W, W u$ W- $L$, Chen $H-H$ : An overview of the Phalaenopsis orchid genome through BAC end sequence analysis. BMC Plant Biol 2011, 11:3.

15. Tsai WC, Hsiao YY, Lee SH, Tung CW, Wang DP, Wang HC, Chen WH, Chen $\mathrm{HH}$ : Expression analysis of the ESTs derived from the flower buds of Phalaenopsis equestris. Plant Sci 2006, 170:426-432.

16. Hsiao YY, Tsai WC, Kuoh CS, Huang TH, Wang HC, Wu TS, Leu YL, Chen WH, Chen $\mathrm{HH}$ : Comparison of transcripts in Phalaenopsis bellina and Phalaenopsis equestris (Orchidaceae) flowers to deduce the monoterpene biosynthesis pathway. BMC Plant Biol 2006, 6:14

17. Tan J, Wang HL, Yeh KW: Analysis of organ-specific, expressed genes in Oncidium orchid by subtractive expressed sequence tags library. Biotechnol Lett 2005, 27:1517-1528.

18. Teh SL, Chan WS, Abdullah JO, Namasivayam P: Development of expressed sequence tag resources for Vanda Mimi Palmer and data mining for EST-SSR. Mol Biol Rep 2010.

19. Tsai WC, Chuang MH, Kuoh CS, Chen WH, Chen HH: Four DEF-like MADS box genes displayed distinct floral morphogenetic roles in Phalaenopsis orchid. Plant Cell Physiol 2004, 45:831-844

20. Tsai WC, Lee PF, Chen HI, Hsiao YY, Wei WJ, Pan ZJ, Chuang MH, Kuoh CS, Chen WH, Chen HH: PeMADS6, a GLOBOSA/PISTILLATA-like gene in Phalaenopsis equestris involved in petaloid formation, and correlated with flower longevity and ovary development. Plant Cell Physiol 2005, 46:1125-1139.

21. Hsiao YY, Jeng MF, Tsai WC, Chung YC, Li CY, Wu TS, Kuoh CS, Chen WH, Chen $\mathrm{HH}$ : A novel homodimeric geranyl diphosphate synthase from the orchid Phalaenopsis bellina lacking a $\mathrm{DD}(\mathrm{X})_{2-4} \mathrm{D}$ motif. Plant J 2008, 55:719-733.

22. Wang CY, Chiou CY, Wang HL, Krishnamurthy R, Venkatagiri S, Tan J, Yeh KW: Carbohydrate mobilization and gene regulatory profile in the pseudobulb of Oncidium orchid during the flowering process. Planta 2008, 227:1063-1077.

23. Margulies M, Egholm M, Altman WE, Attiya S, Bader JS, Bemben LA, Berka J, Braverman MS, Chen YJ, Chen Z, Dewell SB, Du L, Fierro JM, Gomes XV Godwin BC, He W, Helgesen S, Ho CH, Irzyk GP, Jando SC, Alenquer ML, Jarvie TP, Jirage KB, Kim JB, Knight JR, Lanza JR, Leamon JH, Lefkowitz SM, Lei M, Li J, Lohman KL, Lu H, Makhijani VB, McDade KE, McKenna MP, Myers EW, Nickerson E, Nobile JR, Plant R, Puc BP, Ronan MT, Roth GT Sarkis GJ, et al: Genome sequencing in microfabricated high-density picolitre reactors. Nature 2005, 437:376-380

24. Delseny M, Han B, Hsing YI: High throughput DNA sequencing: The new sequencing revolution. Plant Sci 2010, 179:407-422.

25. Cheung F, Haas BJ, Goldberg SM, May GD, Xiao Y, Town CD: Sequencing Medicago truncatula expressed sequenced tags using 454 Life Sciences technology. BMC Genomics 2006, 7:272.

26. Emrich SJ, Barbazuk WB, Li L, Schnable PS: Gene discovery and annotation using LCM-454 transcriptome sequencing. Genome Res 2007, 17:69-73.

27. Varshney RK, Nayak SN, May GD, Jackson SA: Next-generation sequencing technologies and their implications for crop genetics and breeding. Trends Biotechnol 2009, 27:522-530.

28. Jones-Rhoades MW, Borevitz JO, Preuss D: Genome-wide expression profiling of the Arabidopsis female gametophyte identifies families of small, secreted proteins. PLoS Genet 2007, 3:1848-1861.

29. Weber AP, Weber KL, Carr K, Wilkerson C, Ohlrogge JB: Sampling the Arabidopsis transcriptome with massive parallel pyrosequencing. Plant Physiol 2007, 144:32-42
30. Ohtsu K, Smith MB, Emrich SJ, Borsuk LA, Zhou R, Chen T, Zhang X, Timmermans MC, Beck J, Buckner B, Janick-Buckner D, Nettleton D, Scanlon MJ, Schnable PS: Global gene expression analysis of the shoot apical meristem of maize (Zea mays L.). Plant J 2007, 52:391-404.

31. Barbazuk WB, Emrich SJ, Chen HD, Li L, Schnable PS: SNP discovery via 454 transcriptome sequencing. Plant J 2007, 51:910-918

32. Novaes E, Drost DR, Farmerie WG, Pappas GJ Jr, Grattapaglia D, Sederoff RR Kirst M: High-throughput gene and SNP discovery in Eucalyptus grandis, an uncharacterized genome. BMC Genomics 2008, 9:312.

33. Barakat A, DiLoreto DS, Zhang Y, Smith C, Baier K, Powell WA, Wheeler N, Sederoff R, Carlson JE: Comparison of the transcriptomes of American chestnut (Castanea dentata) and Chinese chestnut (Castanea mollissima) in response to the chestnut blight infection. BMC Genomics 2009, 9.51.

34. Alagna F, D'Agostino N, Torchia L, Servili M, Rao R, Pietrella M, Giuliano G, Chiusano ML, Baldoni L, Perrotta G: Comparative 454 pyrosequencing of transcripts from two olive genotypes during fruit development. BMC Genomics 2009, 10:399.

35. Trick M, Long Y, Meng J, Bancroft I: Single nucleotide polymorphism (SNP) discovery in the polyploid Brassica napus using Solexa transcriptome sequencing. Plant Biotechnol J 2009, 7:334-346.

36. Wang W, Wang Y, Zhang Q, Qi Y, Guo D: Global characterization of Artemisia annua glandular trichome transcriptome using 454 pyrosequencing. BMC Genomics 2009, 10:465.

37. Christenson EA. Phalaenopsis. Portland, OR. Timber Press; 2001

38. Lin S, Lee HC, Chen WH, Chen CC, Kao YY, Fu YM, Chen YH, Lin TY: Nuclear DNA contents of Phalaenopsis species and Doritis pulcherrima. J Am Soc Hortic Sci 2001, 126:195-199.

39. Kao YY, Chang SB, Lin TY, Hsieh CH, Chen YH, Chen WH, Chen CC: Differential accumulation of heterochromatin as a cause for karyotype variation in Phalaenopsis orchids. Ann Bot 2001, 87:387-395.

40. Belarmino MM, Mii M: Agrobacterium-mediated genetic transformation of a Phalaenopsis orchid. Plant Cell Rep 2000, 19:435-442.

41. Mishiba K, Chin DP, Mii M: Agrobacterium-mediated transformation of Phalaenopsis by targeting protocorms at an early stage after germination. Plant Cell Rep 2005, 24:297-303.

42. Chan YL, Lin KH, Liao LJ, Chen WH, Chan MT: Gene stacking in Phalaenopsis orchid enhances dual tolerance to pathogen attack. Transgenic Res 2005, 14:279-288.

43. Lu HC, Chen HH, Tsai WC, Chen WH, Su HJ, Chang DCN, Yeh HH: Strategies for functional validation of genes involved in reproductive stages of orchids. Plant Physiol 2007, 143:558-569.

44. Fu CH, Chen YW, Hsiao YY, Pan ZJ, Liu ZJ, Huang YM, Tsai WC, Chen HH: OrchidBase: A collection of sequences of transcriptome derived from orchids. Plant Cell Physiol 2011, 52:238-243.

45. Swarbreck D, Wilks C, Lamesch P, Berardini T, Garcia-Hernandez M, Foerster H, Li D, Meyer T, Muller R, Ploetz L, Radenbaugh A, Singh S, Swing V, Tissier C, Zhang P, Huala E: The Arabidopsis Information Resource (TAIR): gene structure and function annotation. Nucleic Acids Res 2007, gkm965

46. Blanc G, Wolfe KH: Widespread Paleopolyploidy in Model Plant Species Inferred from Age Distributions of Duplicate Genes. Plant Cell 2004, 16:1667-1678.

47. Cui L, Wall PK, Leebens-Mack JH, Lindsay BG, Soltis DE, Doyle JJ, Soltis PS, Carlson JE, Arumuganathan K, Barakat A, Albert VA, Ma H, dePamphilis CW: Widespread genome duplications throughout the history of flowering plants. Genome Res 2006, 16:738-749.

48. Libault M, Joshi T, Benedito VA, Xu D, Udvardi MK, Stacey G: Legume transcription factor genes: What makes legumes so special? Plant Physiol 2009, 151:991-1001.

49. Nelson DR, Schuler MA, Paquette SM, Werck-Reichhart D, Bak S: Comparative genomics of rice and Arabidopsis. Analysis of 727 cytochrome P450 genes and pseudogenes from a monocot and a dicot. Plant Physiol 2004, 135:756-772.

50. Nelson DR, Ming R, Alam M, Schuler MA: Comparison of cytochrome P450 genes from six plant genomes. Trop Plant Biol 2008, 1:216-235.

51. Hsu YF, Tzeng JD, Liu MC, Yei FL, Chung MC, Wang CS: Identification of anther-specific/predominant genes regulated by gibberellin during development of lily anthers. J Plant Physiol 2008, 165:553-563.

52. Van de Peer $Y$, Maere $S$, Meyer A: The evolution significance of ancient genome duplications. Nat Rev Genet 2009, 10:725-732 
53. Soltis DE, Albert VA, Leebens-Mack J, Bell CD, Andrew H. Paterson AH, Zheng C, Sankoff D, dePamphilis CW, Wall PK, Soltis PS: Polyploidy and angiosperm diversification. Am J Bot 2009, 96:336-348.

54. Li Z, Thomas TL: PEI1, an embryo-specific zinc finger protein gene required for heart-stage embryo formation in Arabidopsis. Plant Cell 1998, 10:383-398.

55. Sonoda Y, Yao S-G, Sako K, Sato T, Kato W, Ohto M-a, Ichikawa T, Matsui M, Yamaguchi J, Ikeda A: SHA1, a novel RING finger protein, functions in shoot apical meristem maintenance in Arabidopsis. Plant J 2007, 50:586-596.

56. $\mathrm{Ko} \mathrm{JH}$, Yang SH, Han KH: Upregulation of an Arabidopsis RING-H2 gene, XERICO, confers drought tolerance through increased abscisic acid biosynthesis. Plant J 2006, 47:343-355.

57. Hilbricht T, Salamini F, Bartels D: CpR18, a novel SAP-domain plant transcription factor, binds to a promoter region necessary for $A B A$ mediated expression of the CDeT27-45 gene from the resurrection plant Craterostigma plantagineum Hochst. Plant J 2002, 31:293-303.

58. Dubouzet JG, Sakuma Y, Ito Y, Kasuga M, Dubouzet EG, Miura S, Seki M, Shinozaki K, Yamaguchi-Shinozaki K: OsDREB genes in rice, Oryza sativa L., encode transcription activators that function in drought-, high-salt- and cold-responsive gene expression. Plant I 2003, 33:751-763.

59. Qin Q-I, Liu J-g, Zhang Z, Peng R-h, Xiong A-s, Yao Q-h, Chen J-m: Isolation, optimization, and functional analysis of the CDNA encoding transcription factor OsDREB1B in Oryza Sativa L. Mol Breeding 2007, 19:329-340.

60. Gutterson N, Reuber TL: Regulation of disease resistance pathways by AP2/ERF transcription factors. Curr Opin Plant Biol 2004, 7:465-471.

61. Agarwal P, Agarwal P, Reddy M, Sopory S: Role of DREB transcription factors in abiotic and biotic stress tolerance in plants. Plant Cell Rep 2006, 25:1263-1274.

62. Elliott RC, Betzner AS, Huttner E, Oakes MP, Tucker W, Gerentes D, Perez P, Smyth DR: AINTEGUMENTA, an APETALA2-like gene of Arabidopsis with pleiotropic roles in ovule development and floral organ growth. Plant Cell 1996, 8:155-168

63. Chen WH, Tseng YC, Liu YC, Chuo CM, Chen PT, Tseng KM, Yeh YC, Ger MJ, Wang HL: Cool night temperature induces spike emergence and affects photosynthetic efficiency and metabolizable carbohydrate and organic acid pools in Phalaenopsis aphrodite. Plant Cell Rep 2008, 27:1667-1675.

64. Altschul SF, Madden TL, Schaffer AA, Zhang J, Zhang Z, Miller W, Lipman DJ: Gapped BLAST and PSI-BLAST: a new generation of protein database search programs. Nucleic Acids Res 1997, 25:3389-3402.

doi:10.1186/1471-2164-12-360

Cite this article as: Hsiao et al:: Gene discovery using next-generation pyrosequencing to develop ESTs for Phalaenopsis orchids. BMC Genomics 2011 12:360.

\section{Submit your next manuscript to BioMed Central and take full advantage of:}

- Convenient online submission

- Thorough peer review

- No space constraints or color figure charges

- Immediate publication on acceptance

- Inclusion in PubMed, CAS, Scopus and Google Scholar

- Research which is freely available for redistribution

Submit your manuscript at www.biomedcentral.com/submit
Biomed Central 